\title{
Editorial
}

\section{From Flixborough to Bhopal: is legislation enough?}

New United Kingdom regulations on the control of industrial major accident hazards (CIMAH) were introduced in $1984,{ }^{1}$ the year marked by the world's worst industrial disaster at Bhopal on 3 December and the massive liquid petroleum gas (LPG) explosion at Mexico City two weeks earlier. The main impetus in the United Kingdom for legislation was the Flixborough explosion in 1974 in which cyclohexane killed 28 people. ${ }^{2}$ The philosophy behind the regulations may be seen in the three reports to the Advisory Committee on Major Hazards (ACMH) which was set up after Flixborough. ${ }^{3-5}$ The CIMAH regulations implement an EEC directive of 1982 and "embrace most of the chemical and petrochemical industries using substances which have dangerous flammable explosive or toxic properties"; the main objectives are "prevention of major accidents arising from industrial activities, the limitation of the effects of such accidents both on man and on the environment, and the harmonisation of the control measures to prevent and limit major accidents in the EEC." 1 That there are implications for health workers in these regulations is to be expected, though the uninitiated may have difficulty spotting these at first sight.

In the United Kingdom there has been a requirement since 1983 to identify and notify hazardous sites under the Notification of Installations Handling Hazardous Substances (NIHHS) regulations (1982) and about 1750 sites have been reported to the Health and Safety Executive (HSE), resulting in awareness by local emergency services, more frequent inspections, and greater planning controls. Two hundred and fifty of these sites now come under the CIMAH regulations as "large inventory top-tier sites" that undertake the more hazardous activities using dangerous substances or storing certain scheduled substances over specified limits. In addition to the general requirements on safe operations and the reporting of major accidents, there are four main specific duties. ${ }^{1}$ The manufacturer is obliged to: prepare a safety case- that is, identify the potential for major accidents and the necessary degree of protection and control-to be updated at least every three years; to create an adequate onsite emergency plan; to arrange for the local public to be informed about the risks, and, finally, the local authority has a duty to prepare an offsite emergency plan incorporating the roles of the local emergency services by using adequate information on the hazards which the occupier should provide. Though for existing installations the safety case does not have to be prepared until 1 January 1989, the emergency plans and the supply of information to the public are phased to be completed by 1 January 1986 .

At the same time as this legislation was developing, there has been much effort on research towards greater understanding of chemical accidents from a predictive viewpoint. The medical consequences of such catastrophes, however, and the lessons for emergency planning have not been given as much attention so far, even though both on and off site emergency plans must attempt to take these into account. Health professionals are likely to become concerned at this stage but may find themselves with little readily available guidance. In their third report the ACMH recommended that the Employment Medical Advisory Service (EMAS) be concerned in the drawing up of emergency plans, ${ }^{5}$ and this national team of occupational medicine experts inside the HSE might therefore be expected to help. But what types of issues are involved?

Risk assessments for technological hazards in which statistical probabilities of an accident are compared with risks in other walks of life are by now familiar. The underlying theme is that any reduction in risk to an acceptable level (acceptable to whom?) has to be weighed against the economic consequences. In Britain a watershed in applied risk assessment was the HSE study of Canvey Island, an area in the Thames estuary containing a high concentration of flammable liquids, ammonia, hydrogen fluoride, LPG, and LNG near a populated area. The chance of a resident in the most exposed location being killed or seriously injured as a consequence of a major accident there was estimated to be about 5 in 10000 a year (the same as the average risk of dying from natural causes for people in the 25-36 age group in England and Wales) but the implementation of numerous safety recommendations, together with refinement of the assessments, eventually reduced this estimate by an order of magnitude. ${ }^{78}$ The complex scientific consid- 
erations that have to be incorporated in a risk equation for a major industrial accident, together with their deficiencies, have been summarised by Barrell. ${ }^{6}$ Despite much research on the types of impact of explosive heat and blast, and the behaviour of gas clouds, "hardware" failure rate information, on which probability calculations have to be based, is still scarce. The importance of human influences on safety is widely acknowledged but not well understood. Information on human responses to toxic, heat, and pressure exposures and the ways of mitigating these is generally sparse. In addition, we know that with many of the scheduled chemicals the range of medical effects of a large release resulting in exposure of fit adult workers, let alone on the young, the elderly, and the chronic sick living in the exposed community, can too frequently only be vaguely surmised. For the scheduled chemical methyl isocyanate, the first opportunity to study its human toxicology on any scale was, tragically, at Bhopal. In the December 1985 issue two papers were published which highlighted and began to rectify this deficiency; in one Salmon et al also examine the role of cyanide, a subject that greatly added to the confusion in treating casualties at Bhopal. ${ }^{9}$ Despite the uncertainties, planners have somehow to arrive at estimates of probabilities for different scales of releases or explosions and their possible impacts. Merely planning for the "worst possible scenario" or, even more arbitrarily, "worst credible" or "worst likely" without regard to its chance of occurrence and a range of health effects is unlikely to reflect the real world.

Planning for the different roles of the emergency services may also face similar difficulties. Flammable releases can result in fires, vapour cloud explosions, or BLEVEs (boiling liquid expanding vapour explosions) which occur if a storage vessel fails suddenly in a fire, and the immediate emergency response to all of these would probably resemble that for other catastrophic fires and explosions. Medical teams may need to be sent to the site of the disaster if a large number of injured require triage or resuscitation, or both, or trapped victims need surgery. In the Mexico City incident 5000 injured were seen in provisional emergency centres after the hospitals became overcrowded; the 1969 wounded were taken to 33 hospitals where 900 were admitted to hospital; altogether about 500 died. ${ }^{10}$ An investigation team sent to Mexico City from the Netherlands Organisation for Applied Scientific Research (TNO) two weeks after the disaster studied the validity of mathematical models of damage effects for risk assessment studies and found that they stood up reasonably well. The large toll of dead and injured was clearly due to a densely populated area having grown up around this large LPG storage and distribution centre and most of the damage had been caused by the fire and pressure effects from several BLEVEs. There were no survivors within $300 \mathrm{~m}$ of the blast and work is continuing on the locations of the dead and injured. ${ }^{10}$

There is little information available on disaster $\frac{C}{\partial}$ management for toxic releases. It is axiomatic that the identification of all accidentally released materials is essential, and whereas this may be rapidly achieved for materials stored in large amounts, such as ammonia or chlorine, the inventory of a burnt down ware- $\overrightarrow{0}$ house, for example, may take weeks to compile. ${ }^{11}$ Furthermore, the products of releases from certain chemical processes, such as occurred at Seveso and $\stackrel{\circ}{\circ}$ Bhopal, may be unpredictable. It is therefore essential $\stackrel{\mathbb{S}}{3}$ that expertise is readily available to undertake rapid testing of areas with known contamination, at least for such mundane materials as asbestos, polychlorinated biphenyls, and lead which might have 웅 been released incidentally or unexpectedly and which could cause much public alarm if discovered later in ${ }_{0}$ even small quantities. In addition, chemical samples should be taken whenever possible from the process plant by chemical engineering experts, not only for establishing the cause of the accident but to determine $\vec{\bullet}$ precisely what chemicals might have been produced in ? any reactions that took place. The toxicological information for helping in the treatment of the exposed will most likely be received by doctors over the telephone from a poisons centre. On the spot experts, however, may well be needed for interpreting these bare facts in the light of local circumstances, and long term effects such as carcinogenicity and teratogenicity may not be adequately considered, even though decisions on urgent evacuation can depend on such issues.

Toxic clouds will remain hazardous over much larger distances than flammable clouds, exposing people sometimes over several kilometres downwind. In any incident where the toxic release has not been well contained the entire potentially exposed population should be surveyed for health effects, not just those who arrive at hospitals, in order to determine exactly who has been exposed and require further evaluation and follow up. Specimens of blood and urine should $\frac{D}{O}$ be taken if indicated and stored for future analysis to confirm, whenever possible, the degree of exposure. $N$ In both flammable and toxic releases morbidity and mortality should be carefully documented, and there $\triangle$ may be a need for long term follow up of survivors. $\omega$ Such epidemiological information gathering is essential for the short and long term medical management 0 of the sufferers as well as for planning preventive mea- $\bar{D}$ sures at similar sites elsewhere in the world, yet to be successful it too must be preplanned. The practical difficulties of rapidly mobilising specialists under emergency conditions may seem overwhelming, but delay brings its own insuperable obstacles of sus- 
picion and conflict between the helped and the helper as the events at Bhopal have shown under the gaze of the world's media.

Most chemical accidents are minor, with little if any exposure of the public, and may be adequately handled by local emergency services, but there is always the possibility that the uncommon but serious pollution incident will be overlooked or mismanaged unless it is possible to call rapidly on the laboratory, toxicological, and epidemiological expertise which local services do not normally possess. Yet there is currently no provision for such back up to local emergency services in the United Kingdom. Unfortunately, there seems to be a general lack of understanding of the need for such expertise, particularly the value of epidemiological assessment. By contrast, over the past 20 years attempts have been made to rationalise the emergency response to natural disasters such as earthquakes and famine, mainly through the application of epidemiological methods. ${ }^{1213}$ There is no reason why such methods should not be applied to technological disasters also. Indeed, some concepts arising from natural disaster research might fruitfully be applied to technological disasters. The vulnerability of types of housing or the characterisation of susceptible populations-for example, the concept of "victimisation" as applied by Frears ${ }^{14}$ to sufferers in the Spanish toxic oil syndrome ${ }^{15}$-are cases in point.

If recent events have taught us anything it is that catastrophic incidents of pollution of air, food, and water may be relied on to be unpredictable, often with unforeseen implications for human health. Legislative frameworks are invaluable for reducing environmental risks, but can never obviate them. Hand in hand with the new legislation must go the resources to develop a rational approach to the investigation and management of major industrial accidents on both the national and international level if health workers and others are to participate in more than just a paper exercise.

Employment Medical Advisory Service (London North Region),

Health and Safety Executive,

Barking, Essex IG11 8HF.

\section{References}

${ }^{1}$ Health and Safety Executive. A guide to the control of industrial major accident hazards regulations 1984. London: HMSO, 1985.

${ }^{2}$ Department of Employment. The Flixborough disaster. Report of the court of inquiry. London: HMSO, 1975.

${ }^{3}$ Health and Safety Commission. Advisory committee on major hazards, first report. London: HMSO, 1976.

${ }^{4}$ Health and Safety Commission. Advisory committee on major hazards, second report. London: HMSO, 1979.

${ }^{5} \mathrm{Health}$ and Safety Commission. Advisory committee on major hazards, third report. London: HMSO, 1984.

${ }^{6}$ Barrell AC. Developments in the control of major hazards. In: The assessment and control of major hazards. Rugby: Institute of Chemical Engineers, 1985:1-12. (ICE symposium series No 93.)

${ }^{7}$ Health and Safety Executive. Canvey: summary of an investigation of potential hazards from operations in the Canvey Island/Thurrock area. London: HMSO, 1978.

${ }^{8}$ Health and Safety Executive. Canvey: a second report. London: HMSO, 1981.

${ }^{9}$ Salmon A, Kerr Muir M, Andersson N. Acute response of methyl isocyanate: a preliminary study of dose response for eye and other effects. Br J Ind Med 1985;42:795-8.

${ }^{10}$ Netherlands Organisation for Applied Scientific Research (TNO). Analysis of the LPG incident in San Juan Ixhuatepec, Mexico City, 19 November 1984. The Hague: TNO, 1985.

${ }^{11}$ Health and Safety Executive. The fire and explosions at $B \& R$ Hauliers, Salford, 25 September 1982. London: HMSO, 1983.

${ }^{12}$ Lechat MF. Natural and man-made disasters. In: Holland WW, Detels R, Knox G, eds. Oxford textbook of public health. Vol 1. History, determinants, scope and strategies. Oxford: Oxford University Press, 1984:119-32.

${ }^{13}$ Seaman J. Epidemiology of natural disasters. Basel: Karger, 1984.

${ }^{14}$ Frears R. The Spanish toxic oil syndrome: some explanations for the pathology and an appraisal of the similarities with other episodes of food adulteration. Disasters 1985;2:134-8.

15 World Health Organisation. Toxic oil syndrome: mass food poisoning in Spain. Copenhagen: WHO, 1984.

\section{Guidance for authors}

The British Journal of Industrial Medicine publishes material that is relevant to any aspect of occupational health. Papers that deal with environmental medicine will also be considered. The journal publishes four types of communication, original papers, short reports (which may include reports of clinical material), editorials, and letters to the Editor. Review articles are normally specially commissioned, and authors should not submit such a review without prior consultation with the Editor.
All material submitted to the journal must be typewritten on one side of the paper only with double spacing and wide margins. Manuscripts must be submitted in triplicate to the Editor, TUC Centenary Institute of Occupational Health, London School of Hygiene and Tropical Medicine, Keppel Street, London WCIE 7HT; they must conform with the recommendations given below. Manuscripts must be written in English and spelling must follow the conventions in the Chambers Twentieth Century Dic- 